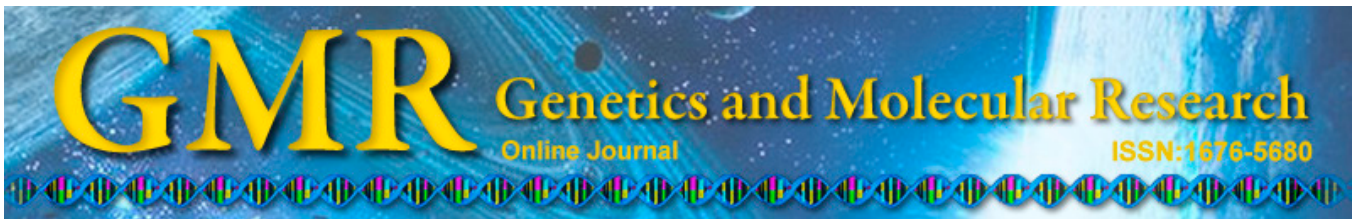

\title{
DNA sequence polymorphism within the bovine adenosine monophosphate deaminase 1 (AMPD1) is associated with production traits in Chinese cattle
}

\author{
C.-B. Wei ${ }^{1,2}$, J.-Q. Wang ${ }^{3}$, F.-Y. Chen ${ }^{2}$, H. Niu ${ }^{3}$ and K. Li ${ }^{1,4}$ \\ ${ }^{1}$ Department of Animal Genetics, Breeding and Reproduction, \\ College of Animal Science and Technology, Nanjing Agricultural University, \\ Nanjing, Jiangsu, China \\ ${ }^{2}$ Institute of Animal Husbandry and Veterinary Medicine, \\ Henan Academy of Agricultural Sciences, Zhengzhou, Henan, China \\ ${ }^{3}$ Research Center of Cattle Engineering Technology in Henan, \\ Zhengzhou, Henan, China \\ ${ }^{4}$ The Key Laboratory for Domestic Animal Genetic Resources and Breeding, \\ Ministry of Agriculture of China, Institute of Animal Science, \\ Chinese Academy of Agricultural Sciences, Beijing, China \\ Corresponding author: K. Li \\ E-mail: kuili@iascaas.net.cn
}

Genet. Mol. Res. 14 (1): 1025-1033 (2015)

Received January 14, 2014

Accepted August 22, 2014

Published February 6, 2015

DOI http://dx.doi.org/10.4238/2015.February.6.6

\begin{abstract}
The objectives of the present study were to detect an 18-bp deletion mutation in the bovine adenosine monophosphate deaminase $1(A M P D 1)$ gene and analyze its effect on growth traits in 2 Chinese cattle breeds using DNA sequencing and agarose electrophoresis. The five 19-bp polymerase chain reaction products of the AMPD1 gene exhibited 3 genotypes and 2 alleles: WW: homozygote genotype (wild-type); DD: homozygote genotype (mutant-type); WD: heterozygote genotype. Frequencies of the $\mathrm{W}$ allele varied from 66.15-
\end{abstract}


$70.35 \%$. The associations between the 18 -bp deletion mutation in the $A M P D 1$ gene with production traits in 226 Jia-Xian red cattle was analyzed. The animals with genotype WW showed significantly higher heart girth and body weight than those with genotypes WD and DD at 24 months $(\mathrm{P}<0.01)$. Our results indicate that the deletion mutation in the $A M P D 1$ gene is associated with production traits, and may be used for marker-assisted selection in beef cattle breeding programs.

Key words: $A M P D 1$ gene; Cattle; Deletion mutation; Production traits

\section{INTRODUCTION}

Adenosine monophosphate deaminase (AMPD) is a complex allosteric enzyme encoded by a multigene family in mammals. Multiple isoforms have been isolated from different human and animal tissues and are named after their source of purification. The AMPD enzyme regulates cellular energy metabolism by participating in purine nucleotide catabolism (Zimmerman, 1992). Subsequent cloning of 3 human genes revealed the molecular basis of 4 different isoforms: AMPD1, isoforms M, muscle; AMPD2, isoforms L, liver; AMPD3, isoforms E1 and E2, erythrocyte (Bausch-Jurken et al., 1992; Mahnke-Zizelman et al., 1996). The 3 AMPD polypeptides share a similar 550-amino acid C-terminal end (62-70\% identical) containing the motif SLSTDDP, which is thought to be the catalytic center of the enzyme (Gross et al., 1994). Conversely, each AMPD polypeptide differs by divergent $\mathrm{N}$-terminal sequences of 200-330 amino acids, with less than 36\% identity to each other.

In humans, the AMPD1 gene is specific to isoform $\mathrm{M}$ and has been cloned and localized to the short arm of chromosome 1 in the region p13-p21 (Sabina et al., 1990). This gene is expressed predominantly in skeletal muscle and is relatively more abundant in type II myofibers. Cis-acting elements located in proximal sequence upstream from the AMPD1 transcriptional start site are required for skeletal myocyte gene expression. AMPD1 is preferentially expressed at high levels in type II skeletal muscle, where it influences the levels of inorganic phosphate, AMP, ADP, and phosphocreatine (Coley et al., 2012). Patients with an inherited defect in AMPD1 expression often have significantly decreased muscle performance, suggesting that the purine nucleotide catabolic pathway plays a role in short-term energy production (Fischer et al., 2007; Norman et al., 2008). The AMPD1 gene is highly expressed in skeletal muscle, and is involved in the rate-limiting step of the purine nucleotide cycle, allowing repletion of ATP stores. AMP deaminase (AMPD; EC 3.5.4.6) catalyzes the hydrolytic deamination of adenosine monophosphate (AMP) to inosine monophosphate (IMP) and ammonium ion. It is expressed predominantly in skeletal muscle and the abundance of this transcript increases during muscle development in vivo and during myocyte differentiation in vitro (Sabina et al., 1989). The skeletal muscle fiber type may be influenced by an AMPD1-dependent transcriptional pathway, and studies examining modulation of the AMPDI gene will contribute to the understanding of muscle development.

In porcine, the $A M P D 1$ gene was found to be involved in energy metabolism closely related to growth and carcass traits (Wang et al., 2008). The AMPD1 gene may be a candidate gene for production trait and provides useful information for further studies on its roles in bovine skeletal muscle. Therefore, we focused on the bovine AMPD1 gene, which may be candidate genes of bovine production traits. 
The purpose of this study was to identify an 18-bp deletion mutation in the bovine ZBED6 gene in 2 Chinese cattle populations. We also conducted association analysis to increase the understanding of the role of ZBED6 in the variation of production traits in cattle, which may be useful for animal breeding and genetic programs.

\section{MATERIAL AND METHODS}

\section{Animal source, DNA preparation and growth data}

Genomic DNA samples were obtained from 356 cows belonging to 2 cattle breeds: Jia-Xian red cattle (JX, N = 226), and Nan-Yang yellow cattle (NY, N = 130). These 2 cattle breeds represent the main breeds of China and are typically reared in the Province of Henan. The Jiaxian animals were from the breeding farm of Jia-Xian Cattle (Jia-Xian County, Henan Province, China); the Nanyang animals were from the Nan-Yang Cattle breeding center (NanYang City, Henan Province, China).

Genomic DNA from 356 cattle were isolated from 2\% heparin-treated blood samples and stored at $-80^{\circ} \mathrm{C}$, following the standard procedures (Sambrook and Russell, 2002).

The 226 cows of the JX breed used for the association study were from a common ancestor, and pedigrees of core breeding population animals were traced back 3 generations. The animals were weaned at an average of 6 months age and raised from weaning to slaughter on a corn silage diet. The growth traits (withers height, body length, heart girth, hucklebone width, and body weight) at 24 months were measured following the method described by Gilbert et al. (1993). All experimental procedures were performed according to authorization granted by the Chinese Ministry of Agriculture.

\section{Primer design and polymerase chain reaction (PCR) amplification}

Primers used to amplify the bovine $A M P D 1$ gene intron 8 locus were designed from a published gene sequence (GenBank accession No. NC_007301). The sequences of the primers: F: 5'-CAA ACA CTC CCT TCT CA-3' (nucleotides 16040-16056); R: 5'-TAG TGC CTG ACC CAA GT-3' (nucleotides 16542-16558). The sizes of expected PCR products were 5 (19 bp, containing all of exon 9 and part of the intron 8 and intron 9 regions (Figure 1).

The 25-mL volume PCR amplification contained 50-100 ng genomic DNA, $10 \mathrm{pM}$ of each primer, $1 \mathrm{X}$ buffer (including $1.5 \mathrm{mM} \mathrm{MgCl}$ ), $200 \mathrm{mM}$ dNTPs, and $1.5 \mathrm{U}$ Taq DNA polymerase (MBI, Vilnius, Lithuania). The PCR protocol for $A M P D 1-\mathrm{F}-\mathrm{R}$ was 3 min at $95^{\circ} \mathrm{C}, 35$ cycles at $94^{\circ} \mathrm{C}$ for $30 \mathrm{~s}, 56^{\circ} \mathrm{C}$ annealing for $40 \mathrm{~s}, 72^{\circ} \mathrm{C}$ for $40 \mathrm{~s}$, and a final extension at $72^{\circ} \mathrm{C}$ for $10 \mathrm{~min}$.

\section{DNA sequencing and agarose electrophoresis analysis}

After polymorphism detection, the $\mathrm{PCR}$ products of different electrophoresis patterns were purified using the DNA Fragment Purification Kit (BIODEV Corp., Beijing, China) and sequenced in both directions (Beijing Aolaibo Biotechnology, China; Applied Biosystems 3730xl DNA Sequencer, Foster city, CA, USA); sequences were analyzed using the BioXM software (Version 2.6).

The 18-bp deletion of the bovine AMPD1 gene was detected. PCR products were 
electrophoresed on 3\% agarose gels with 1 X TBE buffer, containing $200 \mathrm{ng} / \mathrm{mL}$ ethidium bromide. A $7-\mathrm{mL}$ aliquot from the PCR was added to $1.5 \mathrm{~mL}$ loading dye $[0.025 \%$ bromophenol blue, $0.025 \%$ xylene cyanol, $40 \%(\mathrm{w} / \mathrm{v})$ sucrose], and the gels were run at a constant voltage $(100 \mathrm{~V})$ for $50 \mathrm{~min}$.

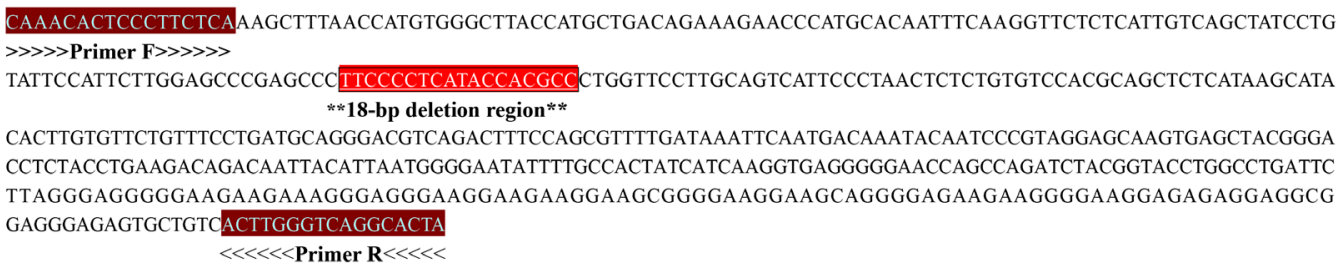

Figure 1. Schematic representation of the 519-bp fragment of the AMPD1 gene (modified output of the bovine AMPD1 gene). Nucleotide sequences for a 519-bp AMPD1 fragment (upper strands) and its bisulfite-converted version (lower strands). Primers sequences are marked with arrows. Squared nucleotides contain 18-bp deletion region ("TTCCCCTCATACCACGCC") for 3\% agarose gel electrophoretic analyses.

\section{Statistical methods}

Gene frequencies were determined for each breed by direct counting. A $\chi^{2}$ test was applied to assess statistical significance using the SPSS software (Version 16.0, SPSS, Inc., Chicago, IL, USA). Population genetic indexes, such as gene heterozygosity $\left(H_{\mathrm{E}}\right)$, effective allele numbers $\left(N_{\mathrm{F}}\right)$, and polymorphism information content (PIC) were calculated according to Nei's methods (Nei and Roychoudhurg, 1974). The formulas were as follows:

$$
H_{o}=\sum_{i=1}^{n} P_{i}^{2} H_{e}=1-\sum_{i=1}^{n} P_{i}^{2} \quad N e=1 / \sum_{i=1}^{n} P_{i}^{2} \quad P I C=1-\sum_{i=1}^{m} P_{i}^{2}-\sum_{i=1}^{m-1} \sum_{j=i+1}^{m} 2 P_{i}^{2} P_{j}^{2} \quad \text { (Equation 1) }
$$

where " $\mathrm{P}_{i}$ " is the frequency of the i allele, " $\mathrm{n}$ " is the number of alleles.

Statistical analysis was performed on records of growth traits in JX cattle. The SPSS software was used to analyze the relationship between the genotypes and traits in cattle. The linear model included fixed effects of age and genotype (Boldman et al., 1995; Zhao et al., 2004). The linear model was as follows:

$$
Y_{i j k}=\mu+A_{i}+G_{j}+E_{i j k} \text {, }
$$

(Equation 2)

where $Y_{i j k}=$ the trait measured on each of the $i j k^{t h}$ animal; $\mu=$ the overall population mean; $A_{i}=$ the fixed effect due to the $i^{i h}$ age; $G_{j}=$ the fixed effect associated with $j^{t h}$ genotype; $E_{i j k}=$ the random error. The least square mean estimates with standard errors for the 2 AMPD1 gene genotypes and growth traits were used. 


\section{RESULTS}

\section{DNA sequencing and genotype distribution}

The bovine AMPD1 gene is located on chromosome 3 and has been revealed to contain 12 exons. To better understand the detailed genetic variation in the bovine AMPD1 gene, DNA sequencing was used. The comparison between nucleotide sequence of bovine AMPD1 gene (GenBank accession No. AC_000160.1) revealed an 18-bp deletion in the intron 8 region of the bovine AMPD1 gene (Figure 2).
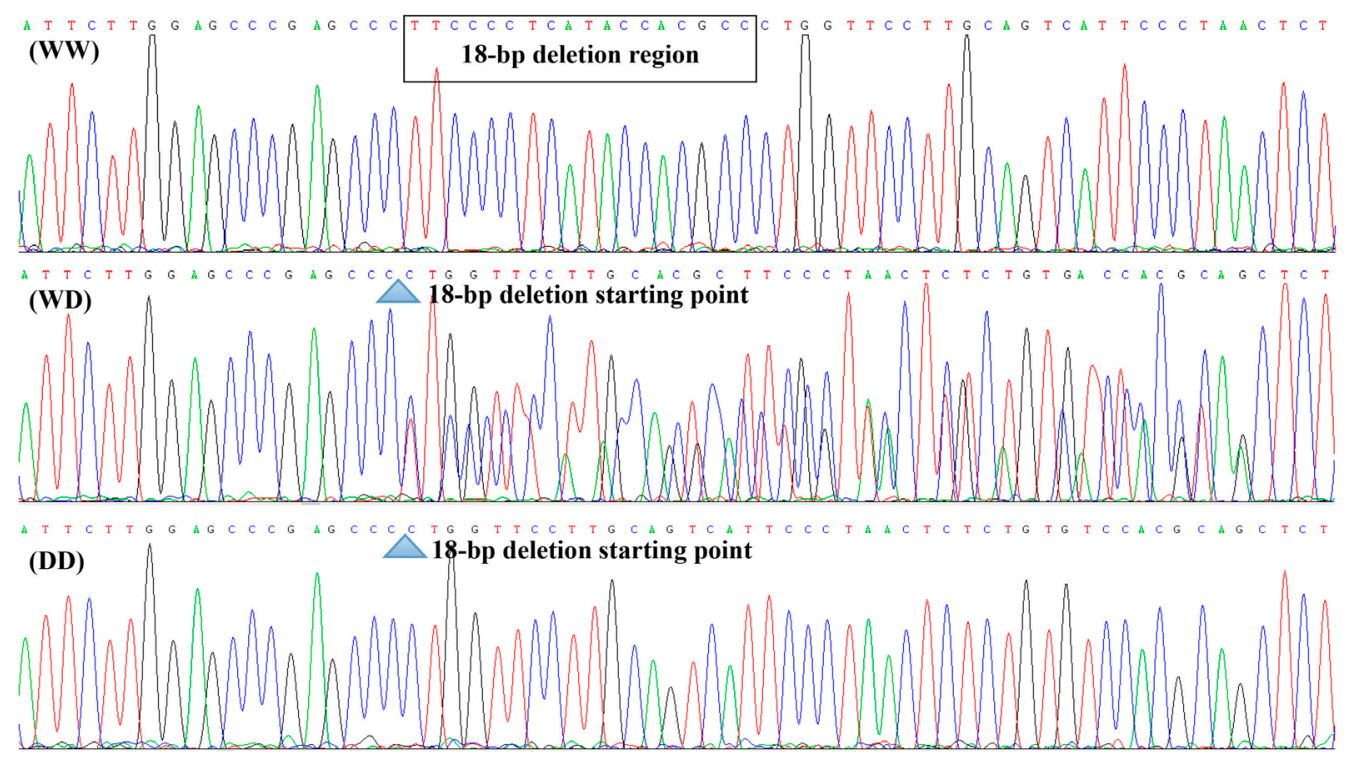

Figure 2. Sequencing and sequence comparison results of the bovine AMPD1 gene. WW $=$ the sequencing results of AMPD1-WW genotype in cattle; WD = the sequencing results of AMPD1-WD genotype in cattle; DD = the sequencing results of AMPD1-DD genotype in cattle.

In this study, the 5 (19-bp) fragment of the AMPD1 gene showed 2 genotypes in the population studied. The fragment lengths of 5 (19 bp for genotype WW, $501 \mathrm{bp}$ for genotype $\mathrm{DD}$, and 5 (19 and $501 \mathrm{bp}$ ) for genotype WD were detected at AMPD1 gene intron 8. We conducted $3.0 \%$ agarose gel electrophoresis to verify the polymorphisms (Figure 3 ).

\section{Diversity analyses}

Frequencies of the AMPD1-W allele in the populations analyzed were 70.35 and $66.15 \%$ for JX and NY, respectively. The frequency of allele $\mathrm{W}$ was higher in the 2 breeds. The $\chi^{2}$ test showed that the genotype distributions within the JX and NY breeds were in HardyWeinberg equilibrium $(\mathrm{P}>0.05$; Table 1$)$, indicating that there was dynamic equilibrium even in artificial selection, migration, and genetic drift function. 


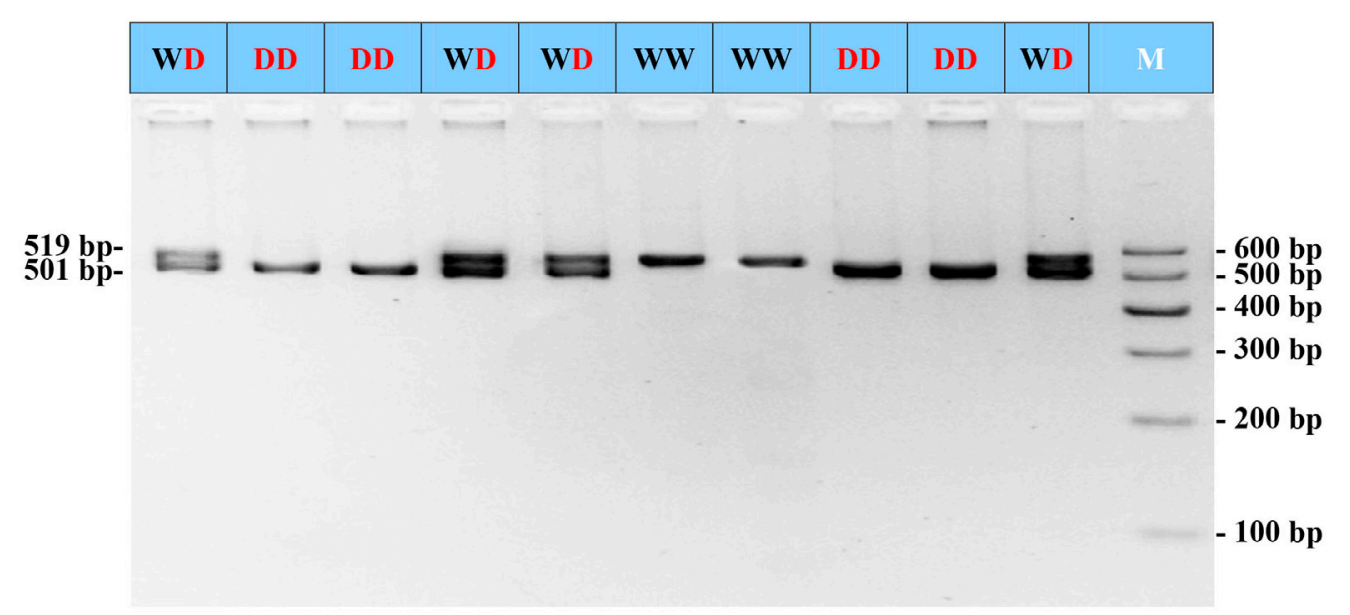

Figure 3. Agarose gel (3\%) electrophoretic patterns of the DNA region containing the intron 8 of the bovine AMPD1 gene. M: marker I (600; 500; 400; 300; 200; 100 bp); WW (519 bp); WD (519 and 501 bp); DD (501 bp).

Genetic indices $\left(H_{\mathrm{E}}, N_{\mathrm{E}}\right.$, and PIC) in these 4 Chinese cattle populations are presented in Table 1 . The values of the observed gene heterozygosity approached 0.5 in the 2 cattle breeds. The maximum and minimum PIC values were 0.3301 and 0.3475 , respectively, and were classified as low (PIC value $<0.25$, low polymorphism; $0.25<$ PIC value $<0.5$, intermediate polymorphism; and PIC value $>0.5$, high polymorphism). The 2 Chinese cattle breeds showed low genetic diversity. This reflected that genetic diversity was not high within the Chinese bovine AMPD1 gene in the populations analyzed.

Table 1. Genotypic and allelic frequencies (\%) and diversity parameter of the bovine AMPD1 gene.

\begin{tabular}{|c|c|c|c|c|c|c|c|c|c|}
\hline \multirow[t]{2}{*}{ Breed (number) } & \multicolumn{3}{|c|}{$\begin{array}{c}\text { Genotype number/ } \\
\text { Genotypic frequency (\%) }\end{array}$} & \multicolumn{2}{|c|}{$\begin{array}{l}\text { Allele/Allelic } \\
\text { frequency (\%) }\end{array}$} & \multirow{2}{*}{$\begin{array}{c}\chi^{2} \\
(\mathrm{HWE})\end{array}$} & \multirow[t]{2}{*}{$\begin{array}{c}H_{\mathrm{E}} \\
\text { (Gene heterozygosity) }\end{array}$} & \multirow[t]{2}{*}{$N_{\mathrm{E}}$} & \multirow[t]{2}{*}{ PIC } \\
\hline & WW & WD & DD & $\mathrm{W}$ & $\mathrm{D}$ & & & & \\
\hline $\begin{array}{l}\text { Jia-Xian red } \\
\text { cattle }(226)\end{array}$ & $118 / 52.22$ & $82 / 36.28$ & $26 / 11.50$ & 70.35 & 29.65 & $3.8310^{*}$ & 0.5828 & 1.7156 & 0.3301 \\
\hline $\begin{array}{l}\text { Nan-Yang yellow } \\
\text { cattle }(130)\end{array}$ & $61 / 46.92$ & $50 / 38.46$ & $19 / 14.62$ & 66.15 & 33.85 & $2.5889 *$ & 0.5522 & 1.8109 & 0.3475 \\
\hline
\end{tabular}

WW = homozygote genotype (wild-type); DD = homozygote genotype (mutant-type); WD = heterozygote genotype. $\chi^{2}(\mathrm{HWE})=$ Hardy-Weinberg equilibrium $\chi^{2}$ value. ${ }^{*}$ Hardy-Weinberg equilibrium $(\mathrm{P}>0.05)$, HardyWeinberg disequilibrium $(\mathrm{P}<0.05) . N_{\mathrm{E}}=$ effective allele numbers. $\mathrm{PIC}=$ polymorphism information content.

\section{Associations between different genotypes and production traits in JX cattle}

We examined the association between polymorphisms in the AMPD1 gene and production traits in the JX breed. Animals with the WW genotype showed higher heart girth and body weight than those with genotypes WD and DD $(\mathrm{P}<0.01)$ at 24 months (Table 2$)$. The remaining records of production traits showed no significant association with the genotype (P $>0.05$ ). Therefore, the presence of the 18-bp deletion mutation in the AMPD1 gene may be a candidate that affects production traits in JX cattle. 


\begin{tabular}{|c|c|c|c|c|}
\hline \multirow[t]{2}{*}{ Phenotypic traits } & \multicolumn{3}{|c|}{ Genotypes (number) } & \multirow[t]{2}{*}{$\mathrm{P}$ value } \\
\hline & WW (118) & WD (82) & DD (26) & \\
\hline Withers height $(\mathrm{cm})$ & $123.571 \pm 1.764$ & $122.34 \pm 0.641$ & $122.562 \pm 1.167$ & 0.805 \\
\hline Body length $(\mathrm{cm})$ & $139.286 \pm 2.638$ & $135.585 \pm 0.959$ & $132.062 \pm 1.745$ & 0.062 \\
\hline Heart girth $(\mathrm{cm})$ & $172.786 \pm 3.034^{\mathrm{A}}$ & $165.547 \pm 1.102^{\mathrm{B}}$ & $159.219 \pm 2.007^{\mathrm{C}}$ & $0.001(\mathrm{P}<0.01)$ \\
\hline Hucklebone width $(\mathrm{cm})$ & $26.929 \pm 0.951$ & $26.047 \pm 0.346$ & $25.687 \pm 0.629$ & 0.556 \\
\hline Body weight (kg) & $384.824 \pm 18.306^{\mathrm{A}}$ & $346.802 \pm 6.653^{\mathrm{B}}$ & $309.931 \pm 12.108^{\mathrm{C}}$ & $0.003(\mathrm{P}<0.01)$ \\
\hline
\end{tabular}

Data are reported as least square means \pm standard errors (means \pm SE). Values with different superscript letters within the same column differ significantly at $\mathrm{P}<0.01$.

\section{DISCUSSION}

Only a few polymorphisms have been detected in the AMPD1 gene. In humans, this has been confounded by a common mutant allele in AMPD1 in Caucasians known as $\mathrm{C} 34 \mathrm{~T}$. This allele introduces a premature stop codon in the second exon of AMPD1, but few studies have examined the 2 major splice variants in $A M P D 1$, the second of which drops exon 2 without affecting enzyme activity (Morisaki et al., 1993). Several human studies have assumed that individuals who are homozygous for $\mathrm{C} 34 \mathrm{~T}$ possess $0 \%$ enzyme activity, resulting in potentially erroneous conclusions. Importantly, 2 different mutations in AMPD1 (R388W and $\mathrm{R} 425 \mathrm{H}$ ) have been identified in Japanese patients with very low AMPD1 enzyme activity and symptoms of myalgia, weakness, and exercise intolerance (Morisaki et al., 2000).

Six single nucleotide polymorphisms were found in animals, representing 3 introduced commercial breeds (Yorkshire, Landrace, and Duroc) and 3 Chinese breeds (Meishan, Tongcheng, and Qingping) of pigs (Wang et al., 2008). Three of the 6 mutations appeared in intronic regions, 1 in exon 11, and 2 in exon 12. The single nucleotide polymorphism (T426C) in the coding region of exon 12 was a synonymous mutation. Association analysis revealed that a single nucleotide polymorphism (T426C) in the coding region of exon 12 of the AMPD1 gene was significantly associated with loin muscle area $(\mathrm{P}<0.01)$, loin muscle height $(\mathrm{P}<$ $0.01)$, and average back fat thickness $(\mathrm{P}<0.05)$. Several previous studies reported that the porcine $A M P D 1$ maps within a known quantitative trait locus with effects on carcass traits such as carcass weight, loin and neck meat weight, loin muscle area, shoulder meat weight, ham meat weight, and chop weight (Geldermann et al., 1999; Walling et al., 2000; Cepica et al., 2003). A new mutation was found in exon 5 (G468T); the G468T transversion is dysfunctional and further indicates that $A M P D 1$ alleles harboring this mutation contribute to the high incidence of partial and complete myoadenylate deaminase deficiency in the Caucasian population (Gross et al., 2002). In cattle, the association between the 18-bp deletion mutation in the AMPD1 gene and body measurement and carcass traits of Qinchuan cattle were analyzed, and the cattle with the AA genotype (wild-type) had slaughter weight and carcass weight greater than those with genotype $\mathrm{AB}(\mathrm{P}<0.01$ or $\mathrm{P}<0.05)$ (He et al., 2010).

\section{CONCLUSIONS}

In this study, the association between the $A M P D 1$ gene and performance traits indicated that the genotype had a significant effect on heart girth and body weight in the JX population. Traits with better performance in the WW genotype can be used for the breeding 
of beef cattle in China. However, further research and validation of the various allelic effects, functional mechanisms, and the bioactivity are needed in an independent sample prior to claiming that the $A M P D 1$ gene 18-bp deletion mutation or others can be used for markerassisted selection in beef cattle.

\section{Conflicts of interest}

The authors declare no conflict of interest.

\section{ACKNOWLEDGMENTS}

Research supported by the Program of National Beef Cattle and Yak Industrial Technology System (Grant \#CARS-38), the National "863" Program of China (Grant \#2008AA101010), the National Science and Technology Major Project of the Ministry of Science and Technology of China during the "11th Five-Year Plan" (\#2008BADB2B03-03), and the Special Funds of the Independent Innovative of Henan Agricultural Academy of Science.

\section{REFERENCES}

Bausch-Jurken MT, Mahnke-Zizelman DK, Morisaki T and Sabina RL (1992). Molecular cloning of AMP deaminase isoform L: sequence and bacterial expression of human AMPD2 cDNA. J. Biol. Chem. 267: 22407-22413.

Boldman KG, Kriese LA, Van Vleck LD, Van Tassell CP, et al. (1995). A manual for use of MTDFREML: a set of programs to obtain estimates of variances and covariances [Draft]. USDA-ARS, Clay Center.

Cepica S, Stratil A, Kopecny M, Blazkova P, et al. (2003). Linkage and QTL mapping for Sus scrofa chromosome 4. J. Anim. Breed. Genet. 120: 28-37.

Coley W, Rayavarapu S, Pandey GS, Sabina RL, et al. (2012). The molecular basis of skeletal muscle weakness in a mouse model of inflammatory myopathy. Arthritis Rheum. 64: 3750-3759.

Fischer H, Esbjörnsson M, Sabina RL, Strömberg A, et al. (2007). AMP deaminase deficiency is associated with lower sprint cycling performance in healthy subjects. J. Appl. Physiol. 103: 315-322.

Geldermann H, Moser G, Muller E, Beeckmann P, et al. (1999). Status of genome and QTL mapping in pigs: data of Hohenheim F2 families. Arch. Tierz. 42: 67-81.

Gilbert RP, Bailey DR Shannon NH (1993). Linear body measurements of cattle before and after twenty years of selection for postweaning gain when fed two different diets. J. Anim. Sci. 71: 1712-1720.

Gross M, Morisaki H, Morisaki T and Holmes EW (1994). Identification of functional domains in AMPD1 by mutational analysis. Biochem. Biophys. Res. Commun. 205: 1010-1017.

Gross M, Rötzer E, Kölle P, Mortier W, et al. (2002). A G468-T AMPD1 mutant allele contributes to the high incidence of myoadenylate deaminase deficiency in the Caucasian population. Neuromuscul. Disord. 12: 558-565.

He H, Liu X, Gu Y and Liu Y (2010). A novel 18-bp deletion mutation of the AMPD1 gene affects carcass traits in Qinchuan cattle. Mol. Biol. Rep. 37: 3945-3949.

Mahnke-Zizelman DK, van den Bergh F, Bausch-Jurken MT, Eddy R, et al. (1996). Cloning, sequence, and characterization of the human AMPD2 gene: evidence for transcriptional regulation by two closely spaced promoters. Biochim. Biophys. Acta 1308: 122-132.

Morisaki H, Morisaki T, Newby LK and Holmes EW (1993). Alternative splicing: a mechanism for phenotypic rescue of a common inherited defect. J. Clin. Invest. 91: 2275-2280.

Morisaki H, Higuchi I, Abe M, Osame M, et al. (2000). First missense mutations (R388W and R425H) of AMPD1 accompanied with myopathy found in a Japanese patient. Hum. Mutat. 16: 467-472.

Nei M and Roychoudhurg AK (1974). Sampling variance of heterozygosity and genetic distance. Genetics 76: $379-390$.

Norman B, Nygren AT, Nowak J and Sabina RL (2008). The effect of AMPD1 genotype on blood flow response to sprint exercise. Eur. J. Appl. Physiol. 103: 173-180.

Sabina RL, Ogasawara N and Holmes EW (1989). Expression of three stage-specific transcripts of AMP deaminase during myogenesis. Mol. Cell. Biol. 9: 2244-2246. 
Sabina RL, Morisaki T, Clarke P, Eddy R, et al. (1990). Characterization of the human and rat myoadenylate deaminase genes. J. Biol. Chem. 265: 9423-9433.

Sambrook J and Russell DW (2002). Molecular Cloning. A Laboratory Manual. Science, Beijing (Translated by Huang Pei Tang).

Walling GA, Visscher PM, Andersson L, Rothschild MF, et al. (2000). Combined analyses of data from quantitative trait loci mapping studies: Chromosome 4 effects on porcine growth and fatness. Genetics 155: 1369-1378.

Wang LJ, Mo X, Xu Y, Zuo B, et al. (2008). Molecular characterization and expression patterns of AMP deaminase1 (AMPD1) in porcine skeletal muscle. Comp. Biochem. Physiol. B Biochem. Mol. Biol. 151: 159-166.

Zhao Q, Davis ME and Hines HC (2004). Associations of polymorphisms in the Pit-1 gene with growth and carcass traits in Angus beef cattle. J. Anim. Sci. 82: 2229-2233.

Zimmerman H (1992). 5ф-Nucleotidase: molecular structure and functional aspects. Biochem. J. 285: 345-365. 